\title{
A Certificação Seletiva Como Auxiliar do Sistema do Mérito
}

\author{
por GEORGE Mc QuoId e \\ Arnold D. Palley (*) \\ tradução de Mary Cardoso
}

$\mathrm{E}_{\mathrm{M}}$

M 1883, quando o sistema do mérito foi pôsto em vigor no âmbito do Govêrno Federal, a admissão de pessoal qualificado para preencher cargos públicos, através de exames amplos e competitivos, constituia problema relativamente simples.

Entretanto, as responsabilidades do Govêrno Federal continuaram crescendo. Onde havia apenas escriturários, passou a haver agrônomos, psicólogos, economistas - milhares de ocupações diferentes. Essa especialização profissional tornou muito mais complicada a administração do sistema do mérito, pois que cada dia era mais difícil promover os exames necessários a cada tipo específico de cargo, cujo número se tornava cada vez maior. Os órgãos de seleção não podiam enfrentar as despesas - algo tinha que ser feito para manter vivo o sistema do mérito e, ao mesmo tempo, manter o custo da seleção dos funcionários federais dentro de limites razoáveis.

Nos primeiros tempos da especialização profissional, ao se tornar impraticável a realização de um exame para cada cargo especializado, a Comissão de Serviço Civil recorreu a uma fórmula nova: a certificação para efeito de seleção, método que consistia em descobrir e certificar, perante os funcionários encarregados das nomeações, os nomes de pessoas que figuravam em listas de elementos qualificados para o exercício de determinadas funções especializadas. E êsse é, ainda hoje, um dos recursos seletivos que ajudam o sistema do mérito a funcionar eficientemente, no moderno cenário empregatício do Govêrno Federal.

(*) Os autores pertencem aos quadros da Comissão de Serviço Civil dos Estados Unidos desde 1951. Trabalham agora como examinadores de qualificações na Divisão de Exames e Enquadramento. 


\section{COMO OPERA A CERTIFICAÇÃO PARA EFEITO DE SEI.EÇÃO}

Do ponto-de-vista de uma autoridade incumbida de nomear, a certificação para efeito de seleção pouco difere da certificação comum. A função dessa autoridade é apresentar uma descrição precisa dos deveres do cargo a ser preenchido; a responsabilidade da escolha da lista de candidatos a ser utilizada e do método de certificação a preferir cabe ao técnico examinador da Comissão de Serviço Civil ou ao corpo de examinadores que receber o pedido de indicação de pessoal.

O examinador faz a revisão das especificações que acompanham o pedido de certificação de candidato e decida sôbre a validade dos registros existentes, quanto a incluirem ou não nomes de pessoas apresentando as qualificações necessárias. Se há entre os registros algum cujas indicações sejam sòmente de pessoas qualificadas, com o treinamento e a experiência necessários ao preenchimento do cargo, não há necessidade de certificação seletiva. Os candidatos serão apenas indicados para a seleção (isto é, serão certificados) de acôrdo com a ordem regular de classificação em que hajam sido colocados.. Se não houver uma classificação dêsse tipo, o examinador pode recorrer à certificação para seleção, revendo os dados que o registro disponivel contenha sôbre os candidatos e certificando para seleção apenas aquêles que possuam as necessárias qualificações específicas.

Boa parte da responsabilidade pelo sucesso a obter no uso do método da certificação cabe ao funcionário que fizer o pedido de indicação de pessoal, pois sòmente quando os deveres e responsabilidades do cargo a preencher são descritos com clareza e exatidão, poderá o examinador determinar, precisamente, as qualificações necessárias. De outro modo, será extremamente difícil identificar o registro adequado, ou certificar indicando os nomes convenientes.

\section{COMO É CONTROLADA A CERTIFICAÇÃO PARA EFEITO DE SELEÇÃO}

A princípio, o uso do método da certificação como instrumento de seleção foi encarado por algumas pessoas como perigosa mutilação dos ideais de um autêntico sistema do mérito. E' verdade que tal instrumento representa uma concessão, mas tendo sido reconhecidos os perigos que lhe são inerentes, a Comissão de Serviço Civil tratou de desenvolver as necessárias cautelas em torno de seu uso.

Objetava-se, contra o emprêgo generalizado da certificação como método seletivo, a possibilidade da nomeação, por autori- 
dades pouco escrupulosas, de pessoa cujo nome não estivesse entre os três primeiros de um determinado registro. Pela circunstância de exigir qualificações especiais, a descrição do cargo poderia vir a ser feita sob medida, de modo a comportar exatamente a escolha do candidato favorecido. Se tal coisa fôsse admitida, estariam as portas sendo reabertas a todos os abusos do favorecimento politico e pessoal.

Outra objeção consistia em que algumas autoridades federais poderiam usar a certificação para estabelecer requisitos de qualificação injustificáveis. As qualificações poderiam vir a ser tão exageradas, em quantidade, que acabariam por eliminar candidatos altamente qualificados, ou, de outro modo, poderiam ser tão exorbitantes qualitativamente que eliminariam candidatos de certas áreas geográficas, ou de certas instituições educacionais. Exemplo de exagêro quantitativo seria exigir que assistentes de laboratório tivessem conhecimentos de cálculo, quando só se lhes deve pedir o domínio de álgebra do nivel secundário, ao passo que a exorbitância qualitativa seria demonstrada se se exigisse de um analista de transporte de nivel inicial o conhecimento dos problemas de comércio maritimo peculiares à área portuária de Nova York. A lei que rege o serviço público civil determina que os padrões estabelecidos para os cargos sejam razoáveis e capazes de. permitir o máximo de livre competição.

Essas duas objeções foram neutralizadas pela fixação de normas específicas, para orientação dos examinadores na decisão das oportunidades em que caberia ou não recorrer à certificação para seleção de candidatos, normas que podem ser resumidas como se segue:

1. As especificações de cargo que acompanham o pedido de certificação baseiam-se nos deveres reais dêsse mesmo cargo?

2. A formação especializada ou a experiência que se exige do candidato foram fixadas em têrmos demasiado rígidos? O critério adotado exclui a consideração de pessoas que possuam outras qualificações que as poderiam habilitar ao desempenho do cargo?

3. São exorbitantes as exigências totais feitas para o cargo? Ultrapassam elas requisitos razoáveis para o desempenho do nivel e tipo de funções que constituem os deveres dêsse mesmo cargo?

4. Um razoável periodo de ajustamento ao trabalho afeto a êsse cargo permitiria a um candidato de qualificação de tipo genérico a aquisição das qualificações especiais descritas? 
5. Tais qualificações são tão caprichosas ou tão peculiares a ponto de indicarem uma tentativa de atingir um determinado nome constante do registro?

6. As especificações de cargo apresentadas baseiam-se numa possivel e futura atribuição de responsabilidade, em vez de considerarem as exigências do trabalho para que os candidatos deverão ser certificados?

Os que criticavam a certificação seletiva nesse periodo inicial, viam-na ainda como uma ameaça a outro princípio básico do sistema do mérito: a ampla divulgação a ser dada sôbre as oportunidades de emprêgo em cargos federais. Quando ocorria inexistir o registro correspondente a um determinado cargo, fazia-se a escolha de elementos qualificados por uma outra lista ocupacional semelhante, mas não exatamente idêntica, ao trabalho que se tinha em vista e, em conseqüência, tais pessoas, eram achadas por acaso, não se tinham candidatado ao cargo eventualmente vago. Desde que tais cidadãos eram encontrados acidentalmente, era óbvio que haveria outros elementos qualificados igualmente disponiveis, que teriam competido pela vaga existente, se um concurso público tivesse sido anunciado. Para tal situação era preciso encontrar remédio.

A solução foi achada nos concursos gerais, promovidos de modo a abranger todos os tipos de trabalho que compõem um campo ocupacional. A realização de um exame dêsse tipo faz o efeito de vários pequenos exames em separado, sem acarretar suas enormes despesas. Anuncia-se o concurso com tal clareza de linguagem que qualquer trabalhador especializado, no quadro geral daquêles que se interessam por emprêgo público, possa ter esperança de conseguir êsse emprêgo através do concurso que vai prestar. Por exemplo, em vez de se dar publicidade à realização de vários diferentes exames para as diversas especialidades em que se classificam os economistas, anuncia-se a realização de um concurso de que podem participar todos os tipos de economista. A identificação do especialista de melhor qualificação para determinado tipo de cargo será obtida mediante a certificação seletiva. $\mathrm{Na}$ prática, os candidatos qualificados são classificados e agrupados segundo as especializações mais freqüentes, nos grandes 
campos ocupacionais, e êsse agrupamento elimina a necessidade de uma completa revisão analítica da relação de candidatos, sempre que surgem pedidos para indicações visando ao preenchimento de cargos especializados.

O concurso geral tem ainda a vantagem de permitir que candidatos qualificados em diversas especialidades possam ser considerados para tôdas elas, sem terem que se candidatar separadamente em cada uma. Alguns dêsses concursos são promovidos para o preenchimento de cargos nos escalōes mais elevados de certas profissões que apresentam grande número de especializações, pois que se verificou, em tais casos, ser de alta conveniência a avaliação dos candidatos à base de qualificações comuns a tôdas as especialidades. De início classifica-se o candidato apenas como qualificado ou não qualificado. Surgindo pedido de determinada autoridade para indicação de elementos credenciados ao preenchimento de certo cargo especializado, a documentação de todos os elementos aptos com experiência no campo especializado de que se trata é então revista em têrmos dos padrões de qualificação fixados para êsse cargo em particular. Os candidatos qualificados recebem uma nota numérica de classificação e são escalonados apenas para os efeitos da certificação para o cargo a ser preenchido. Êsse tipo de exame exemplifica um refinamento dos principios que fundamentam o concurso geral. A identificação dos especialistas qualificados não é feita através da certificação seletiva, mas antes através da utilização de uma prática que leva o exame competitivo aos mais limitados setores da especialização profissional.

O concurso geral mostrou também que constitui método prático para a preservação do princípio da ampla competição. Nos últimos anos, tem sido aplicado a um número cada vez maior de áreas ocupacionais, embora não se possa afirmar antecipadamente que seu uso se expandirá até abranger cada um dos cargos especializados que se encontram no serviço público federal. Na proporção em que ainda se faz uso da certificação para efeito de seleção independentemente dos concursos gerais, existe também certa ameaça à plena operação do sistema da competição ampla, mas com razoável cautela será possível tornarem-se mínimos tais riscos, conseguindo-se vantagens consideráveis. 
Assim, a certificação seletiva representa um método que ajuda o sistema do mérito a funcionar. Quisemos salientar aqui alguns dos perigos que decorrem de sua aplicação, bem como as providências que foram adotadas para minimizá-los. E' verdade que nem todos êsses perigos foram eliminados e que, se as normas postas em prática através dos anos pela Comissão de Serviço Civil muito contribuíram para tornar a certificação seletiva um instrumento de trabalho útil, sua conveniente aplicação não é automática. O uso inteligente dêsse método depende de uma sadia atitude de cooperação entre o examinador e o órgão público a ser servido.

(In "Personnel Administration [Administração de Pessoal]", vol. 16, n? 3, págs. 15 e segs.). 